\title{
Financial Performance Evaluation of Listed Commercial Banks in China
}

\author{
Guang-yin TONG ${ }^{1}$, Zhen-yu LIU ${ }^{2,}$ and Can HUANG ${ }^{3}$ \\ 'Zaozhuang University, Zaozhuang, Chia; Silla University, Busan, Korea \\ ${ }^{2}$ Zaozhuang University, Zaozhuang, Chia \\ ${ }^{3}$ Yicheng District of Zaozhuang State Taxation Bureau, Zaozhuang, Chia \\ ${ }^{*}$ Corresponding author
}

Keywords: Listed commercial banks, Financial performance, Principal component analysis.

\begin{abstract}
A comprehensive and objective evaluation of the financial performance of Listed Companies in banking industry is great significance not only for their own profits and long-term development, but also for building a prosperous and orderly financial environment. This paper selected 20 commercial banks listed on the A stock market, by means of principal component analysis in the software SPSS17.0 10 financial indicators, the ranking of the 20 commercial banks at the end of 2016, financial performance and reveals the existing problems, And some suggestions are put forward from the perspective of the performance management of the listed commercial banks.
\end{abstract}

\section{中国上市商业银行财务绩效评价}

\author{
童广印1, 刘振宇 $2^{*}$, 黄灿 ${ }^{3}$ \\ 1本庄学院 经济与管理学院, 本庄, 中国; 新罗大学税务会计系, 釜山, 韩国 \\ 2本庄学院 经济与管理学院, 東庄, 中国 \\ 3冭庄市峄城区国家税务局, 畨庄, 中国 \\ “通讯作者
}

关键词：上市商业银行；财务绩效；主成分分析法

摘要：对银行业上市公司财务绩效全面客观的评价, 不仅对其自身盈利和长远发展具有重要 的意义，同时对于建立繁荣有序的金融环境也具有深远的影响。本文选取在A 股市场上市的 20 家商业银行, 通过SPSS17.0软件中的主成分分析法对其2016年末的10项财务指标进行分析, 得出了这20家商业银行2016年末的财务绩效排名, 揭示其财务绩效存在的问题, 并从上市商 业银行绩效管理视角提出了相关建议。

\section{1. 引言}

作为以金融货币经营为主要业务的商业银行, 其主要业务类型包括负债业务、资产业务 和中间业务，其业务范围涵盖了我国经济金融领域的大部分，是维护我国金融市场秩序健康、 稳定和有序发展的重要基础。我国商业银行在以获取利润为主要目的的日常经营过程中, 主 要承担了支付中介、金融服务、信用创造和经济调节等多项金融领域特定职能, 为其他金融 机构的运行和发展提供了共同平台。因此, 适时跟踪研究和评价我国商业银行的财务绩效, 有着重要的现实意义和决策参考价值。 


\section{2. 财务绩效评价指标选择和样本数据来源}

\section{1 财务绩效评价指标选择}

运用SPSS软件中的主成分分析法全面客观地评价我国商业银行财务绩效的关键是恰当 的选择相应的财务指标。综合考虑我国上市商业银行财务指标的可得性和有效性，从反映财 务绩效状况的运营性指标、安全性指标、盈利性指标和发展性指标等四个维度选取了4类10 个具体财务指标。具体指标名称及其计算公式如下:

运营指标：总资产周转率 $\mathrm{X} 1=$ 营业收入 / 平均资产总额; 应收账款周转率 $\mathrm{X} 2=$ 营业收入 / 应收账款平均占用额; 现金及现金等价物周转率X3=营业收入 / 现金及现金等价物平均余额。

安全指标: 资产负债率 X4 $=$ 负债合计 / 资产总计; 负债与权益市价比率X $5=$ 负债合计 / 市 值。

盈利指标: 投资收益率X6=本期投资收益/（长期股权投资本期期末值+持有至到期投资本 期期末值 + 交易性金融资产本期期末值 + 可供出售金融资产本期期末值 + 衍生金融资产本期期 末值）; 净资产收益率 $\mathrm{X} 7=$ 净利润 / 股东权益平均余额; 总资产净利润率 $\mathrm{X} 8=$ 净利润 / 总资产 平均余额。

发展指标：权益乘数 $\mathrm{X} 9=$ 资产总额/股东权益总额; 可持续增长率 $\mathrm{X} 10=$ 净资产收益率*收 益留存率/（1-净资产收益率*收益留存率）。

\section{2 样本数据来源}

综合考虑财务分析数据的可得性和有效性，本文选取了 2017年4月底在沪深A 股上市的所 有商业银行发布的 20 余家财务报告为样本。剔除截止 2017 年 4 月底尚未发布 2016 年末数据和个 别数据缺失的样本, 共 20 家商业银行财务报告样本。本文研究的数据均来自这 20 家上市商业 银行对外公布的2016年年末的合并会计报表年报。

\section{3. 实证分析}

本文用SPSS 17.0 软件中的主成分分析法对20家上市商业银行的2016年末合并会计报表 中选择的10项指标数据进行处理。

\section{1 取样适当性（KMO）检验}

从表 1 可以看出, 样本的取样适切性量数 (KMO) 统计值为 0.600 , 表明这 20 家商业银行 的财务指标数据适合进行主成分分析。在Bartlett的球形度检验中，其卡方统计值为 219.830 , 自由度为 45 , 显著性概率为 0.000 , 小于显著性水平, 拒绝Bartlett的球形度检验的零假设, Bartlett的球形度检验综合结果也表明可以考虑进行因子分析。因而, 初步判断, 采用主成分 分析法进行数据处理, 文中所有评价指标要反映的信息量能够被所获得的公因子涵盖, 我国 上市商业银行的财务绩效水平能够被客观反映出来。

表1 KMO 和巴特利特检验

\begin{tabular}{|c|c|c|}
\hline \multicolumn{2}{|c|}{ KMO 取样适切性量数 } & .600 \\
\hline \multirow{3}{*}{ Bartlett 的球形度检验 } & $\begin{array}{c}\text { 上次读取的 } \\
\text { 卡方 }\end{array}$ & 219.830 \\
\cline { 2 - 3 } & \begin{tabular}{c} 
自由度 \\
\cline { 2 - 3 }
\end{tabular} & 45 \\
\hline 显著性 & .000 \\
\hline
\end{tabular}

\section{2 共同性检查}

表2 共同性检查

\begin{tabular}{|r|c|c|}
\hline & 初始值 & 提取 \\
\hline 总资产周转率X1 & 1.000 & .715 \\
\hline
\end{tabular}




\begin{tabular}{|r|c|c|}
\hline 应收账款周转率X2 & 1.000 & .940 \\
\hline 现金及现金等价物周转率X3 & 1.000 & .953 \\
\hline 资产负债率X4 & 1.000 & .367 \\
\hline 负债与权益市价比率X5 & 1.000 & .710 \\
\hline 投资收益率X6 & 1.000 & .668 \\
\hline 净资产收益率X7 & 1.000 & .948 \\
\hline 总资产净利润率X8 & 1.000 & .894 \\
\hline 权益乘数X9 & 1.000 & .698 \\
\hline 可持续增长率X10 & 1.000 & .922 \\
\hline
\end{tabular}

\section{3 方差贡献率检查}

在表3列示的方差贡献率检验中, 特征值大于1的因素, 共有3个, 分别为(3.456)、（3.293）、 （1.066），变异量分别为（34.561）、（32.929）、（10.658）。这3个因素形成的3个主因子 已经解释了原指标变量标准化方差的 $78.148 \%$, 即用这 3 个主因子所代表的信息量替代原来 10 个原始指标内涵的信息量, 客观评价我国上市商业银行的财务绩效水平有大于 $78 \%$ 的把握。

表3 方差贡献率检验

\begin{tabular}{|c|c|c|c|c|c|c|c|c|c|}
\hline \multirow[b]{2}{*}{$\begin{array}{l}\text { 组 } \\
\text { 件 }\end{array}$} & \multicolumn{3}{|c|}{ 初始特征值 } & \multicolumn{3}{|c|}{ 提取载荷平方和 } & \multicolumn{3}{|c|}{ 旋转载荷平方和 } \\
\hline & 总计 & $\begin{array}{c}\text { 方差百分 } \\
\text { 比 }\end{array}$ & 累积 \% & 总计 & $\begin{array}{c}\text { 方差百分 } \\
\text { 比 }\end{array}$ & 累积 \% & 总计 & $\begin{array}{l}\text { 方差百 } \\
\text { 分比 }\end{array}$ & 累积 \% \\
\hline 1 & 3.839 & 38.386 & 38.386 & 3.839 & 38.386 & 38.386 & 3.456 & 34.561 & 34.561 \\
\hline 2 & 2.965 & 29.652 & 68.038 & 2.965 & 29.652 & 68.038 & 3.293 & 32.929 & 67.490 \\
\hline 3 & 1.011 & 10.110 & 78.148 & 1.011 & 10.110 & 78.148 & 1.066 & 10.658 & 78.148 \\
\hline 4 & .844 & 8.438 & 86.586 & & & & & & \\
\hline 5 & .700 & 6.996 & 93.582 & & & & & & \\
\hline 6 & .341 & 3.414 & 96.996 & & & & & & \\
\hline 7 & .270 & 2.696 & 99.692 & & & & & & \\
\hline 8 & .017 & .169 & 99.861 & & & & & & \\
\hline 9 & .011 & .107 & 99.967 & & & & & & \\
\hline 10 & .003 & .033 & 100.000 & & & & & & \\
\hline
\end{tabular}

另外, 在碎石图（图1）中，横坐标为主成分分析法萃取的各因子序号，纵坐标列示的是 各因子对应的特征值, 从图中可以看出因子的重要程度。将横坐标和纵坐标的值分别描点, 将得到的点用直线依次连接，最后得到了如图1所示的折线图，图中显示前 3 个因子的之间的 连线的坡度相对较陡, 比较陡的线段说明其两个端点所对应因子特征值的差值较大, 进一步 表明两者内涵的信息属性有较大差别。处于拐点位置的是第3个因子，这表明第四个因子之后 的因子具有相对类似的信息属性，并且其反应的信息可以被前 3 个因子揭示。所以，本文把前 3 个因子作为主要因子。

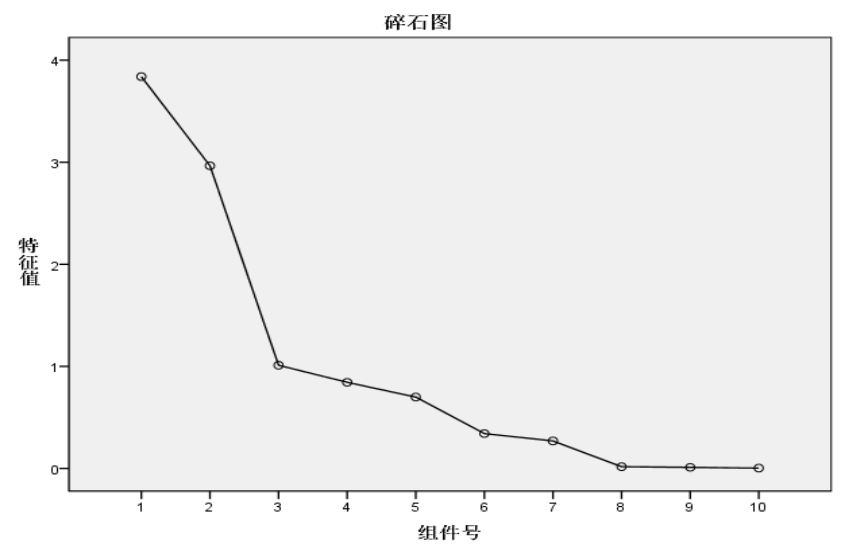

图1 碎石图 


\section{4 分析转轴后的因素矩阵}

对初始因子载荷矩阵做方差最大正交旋转。结果如表4所示, 旋转后的因子载荷系数的数 值已经出现较为明显的两极分化, 具有了对我国上市商业银行财务绩效较好的解释力和经济 意义。接下来对获得的 3 个主要因子进行解释和命名如下:

$\mathrm{F} 1$ 作为第一主因子，其在X2、X3、X4、X6和X10上的因子载荷值较大，而这些指标主要 反映的是我国上市商业银行资产运营和发展方面的能力, 可以称F1为运营发展因子; F2作为 第二主因子, 其在X5、X7、X8上的因子载荷值较大，这三个指标均主要反映的是企业的盈利 能力, 可以称 $F 2$ 为盈利能力因子; F3 作为第三主因子, 其在 $X 1 、 X 9$ 上的因子载荷值较大, 这 两个指标主要反映资产财务安全能力, 因此可以称F3为资产安全因子。

表4 旋转后的成分矩阵 ${ }^{\mathrm{a}}$

\begin{tabular}{|c|c|c|c|}
\hline & \multicolumn{3}{|c|}{ 组件 } \\
\hline & 1 & 2 & 3 \\
\hline 现金及现金等价物周转率X3 & .925 & & \\
\hline 可持续增长率X10 & .920 & & \\
\hline 应收账款周转率X2 & .896 & & \\
\hline 投资收益率X6 & .669 & & .469 \\
\hline 资产负债率X4 & .552 & & \\
\hline 净资产收益率X7 & & .962 & \\
\hline 总资产净利润率X8 & & .937 & \\
\hline 负债与权益市价比率X5 & & -.831 & \\
\hline 总资产周转率X1 & .415 & .615 & -.405 \\
\hline 权益乘数X9 & & & .773 \\
\hline
\end{tabular}

\section{5 财务绩效综合得分的计算及结果排序}

在SPSS17.0软件中, 根据主成分分析法进行的数据处理得到的 3 个主因子上的得分数据 （表5中的FAC1_1，FAC2_1，FAC3_1）以及表3中各因子的方差贡献率与总解释方差比率, 确定我国上市商业银行财务绩效评价模型:

$\mathrm{Fi}=\left(34.561 * \mathrm{FAC} 1 \_1+32.929 * \mathrm{FAC} 2 \_1+10.658 * \mathrm{FAC} 3 \_1\right) / 78.148$

其中, $F i$ 为某一家商业银行绩效总得分 $(i=1,2,3, \ldots, 20$; 比如 $F 1$ 表示平安银行的财 务绩效综合得分）。

借助EXCEL软件的数据计算, 得出我国20家上市商业银行的财务绩效综合得分并排序, 如表5 所示。

表5 因子综合得分及排序

\begin{tabular}{|c|c|c|c|c|c|c|c|c|c|}
\hline \multirow{2}{*}{$\begin{array}{c}\text { 股票代 } \\
\text { 码 }\end{array}$} & \multirow[b]{2}{*}{ 股票名称 } & \multicolumn{6}{|c|}{ 主因子得分及排序 } & \multirow[b]{2}{*}{ 综合得分 } & \multirow{2}{*}{$\begin{array}{l}\text { 排 } \\
\text { 序 }\end{array}$} \\
\hline & & FAC1_1 & $\begin{array}{l}\text { 排 } \\
\text { 序 }\end{array}$ & FAC2_1 & $\begin{array}{l}\text { 排 } \\
\text { 序 }\end{array}$ & FAC3_1 & $\begin{array}{l}\text { 排 } \\
\text { 序 }\end{array}$ & & \\
\hline 000001 & 平安银行 & -0.17929 & 10 & -0.03648 & 12 & 0.85051 & 6 & -0.07619 & 13 \\
\hline 002807 & 江阴银行 & -1.28303 & 18 & -2.03377 & 20 & -1.34513 & 18 & -1.42927 & 20 \\
\hline 600000 & 浦发银行 & 0.80994 & 5 & 0.91199 & 3 & -0.64363 & 15 & 0.718216 & 3 \\
\hline 600016 & 民生银行 & 43606 & 6 & 0.63461 & 7 & & 2 & 8459 & 4 \\
\hline 600036 & 招商银行 & 1.34414 & 3 & 0.46298 & 8 & -1.52179 & 19 & 0.751859 & 2 \\
\hline 600908 & 无锡银行 & -1.39553 & 19 & -0.26244 & 14 & -1.13115 & 17 & $\begin{array}{l}-0.7487 \\
\end{array}$ & 19 \\
\hline 600919 & 江苏银行 & -0.81146 & 16 & 1.41801 & 1 & -0.10277 & 10 & 0.21996 & 7 \\
\hline 600926 & 杭州银行 & -1.4118 & 20 & 1.3838 & 2 & -0.38931 & 12 & -0.06564 & 12 \\
\hline 601009 & 南京银行 & 0.24412 & 8 & 0.86414 & 4 & 0.56875 & 8 & 0.474098 & 5 \\
\hline 601128 & 常熟银行 & -0.30208 & 12 & -1.21806 & 18 & -0.39599 & 13 & -0.64108 & 18 \\
\hline 601169 & 北京银行 & -0.34067 & 13 & 0.26113 & 11 & -0.65575 & 16 & -0.05758 & 11 \\
\hline
\end{tabular}




\begin{tabular}{|c|c|c|c|c|c|c|c|c|c|}
\hline 601229 & 上海银行 & -0.18419 & 11 & 0.82525 & 5 & -1.59867 & 20 & 0.222758 & 6 \\
\hline 601288 & 农业银行 & 0.31466 & 7 & -0.25843 & 13 & 1.08133 & 4 & 0.056212 & 9 \\
\hline 601328 & 交通银行 & -0.60322 & 15 & -0.5294 & 15 & 1.0151 & 5 & -0.46215 & 17 \\
\hline 601398 & 工商银行 & 1.01113 & 4 & -1.65909 & 19 & -0.23702 & 11 & -0.23764 & 15 \\
\hline 601818 & 光大银行 & -0.53205 & 14 & 0.40391 & 9 & 1.63724 & 1 & -0.03507 & 10 \\
\hline 601939 & 建设银行 & 1.47972 & 2 & -1.11347 & 16 & 0.83591 & 7 & 0.215914 & 8 \\
\hline 601988 & 中国银行 & 0.01182 & 9 & -1.12251 & 17 & 0.37591 & 9 & -0.44673 & 16 \\
\hline 601997 & 贵阳银行 & 2.25188 & 1 & 0.76488 & 6 & -0.63995 & 14 & 1.295716 & 1 \\
\hline 601998 & 中信银行 & -0.86013 & 17 & 0.30297 & 10 & 1.09032 & 3 & -0.23312 & 14 \\
\hline
\end{tabular}

\section{4. 结论及建议}

从表5中我国上市商业银行综合得分排序结果来看，2016年度财务绩效水平综合排名第1 位的是贵阳银行, 财务绩效表现最好; 排名第20位的是江阴银行, 表现最差。国有四大商业 银行中，财务绩效表现较好的是中国建设银行和中国农业银行，综合排名分别为第8位和第 9 位; 较差的是中国工商银行和中国银行, 综合排名分别为第15位和第16位。在股份制商业银 行中, 财务绩效表现最好的是招商银行, 综合排名第2位, 紧跟其后的是浦发银行和民生银行, 综合排名分别为第3和第4位, 光大银行, 平安银行的表现中等。最差的是中信银行, 综合排 名第14位。城市商业银行中, 除贵阳银行财务绩效表现最好外, 南京银行、上海银行和江苏 银行的财务绩效水平也比较高, 综合排名为第5、第6和第7位。

从各主因子排序结果看, 运营发展方面, 贵阳银行、建设银行和招商银行表现出色; 盈 利能力方面, 江苏银行、杭州银行和浦发银行表现分列前三名; 资产安全方面, 广大银行、 民生银行和中信银行表现最好。

从我国上市商业银行发展现状来看，城市商业银行总体财务绩效表现较高的原因，可能 与地方性政策的支持和其本身规模不大有关，并不能说明它们企业发展的软实力就已经很强。 工商银行仍然是全世界范围内资产规模最大的上市商业银行, 但是在2016年的财务绩效评价 中的综合表现特别是盈利方面的表现却不如贵阳银行这样的城市商业银行。此外，建设银行、 中国银行的盈利性表现均较差, 其特征也就是资本安全性和运营发展表现还算过得去。这种 现象, 也同样在一些大型的股份制商业银行中出现。因此, 对于我国大型的国有和股份制上 市商业银行来说，企业的盈利性和运营性的全面协调发展才是其未来发展模式的关键。

\section{References}

[1] Huang Mengqi. Research on financial performance of commercial banks in China -- An Empirical Analysis Based on factor analysis method [J]. finance and economy, 2015,03:45-50.

[2] Ji Jianyue, Fu Yangyu, Wang Cui. Stakeholder relationship and the financial performance of commercial banks -- Based on the panel data of listed banks Chinese empirical analysis of [J]. financial forum, 2012,12:64-72.

[3] Shang Guanfei, Shu Changjiang. Performance evaluation of China Commercial Bank Based on factor analysis. Economic problem [J].2011, 1:109-111.

[4] Xie Juan, Yu Yi. Financial performance evaluation of commercial banks [J]. finance and accounting communication, 2010,17:28-29.

[5] E Zhaodi, Chen Hong. China's commercial banks financial performance evaluation system of [J]. productivity research, 2009,22:56-57+60. 